\title{
PEDAGOGIA DA ALTERNÂNCIA
}

\section{CAMBIANDO DE PEDAGOGÍA}

\section{ALTERNATING FROM PEDAGOGY}

\section{Edna Maria Silva Oliveira GODINHO ${ }^{1}$}

RESUMO: Aqui será abordada a pedagogia em três âmbitos: rural, do campo e da Alternância. A pedagogia oferece inúmeros meios para o ensino/aprendizagem em qualquer espaço ou território onde se encontra a vontade de aprender, a busca pelo conhecimento ou mesmo o desejo de conhecer. Esse conhecimento vem da família, dos amigos, da escola, em todos os lugares onde vivemos. A Alternância descreve mudanças para o aprendizado, no âmbito descritivo, com base cultural de cada individuo do grupo, da família, dos amigos mais ou mesmo de grupos religiosos. Essa metodologia educacional tem inicio nos anos 90 e tem balizada em pesquisas científicas. Este método está implícito na proposta de Jean Piaget, fazer pra compreender, ou seja, primeiro praticar, para depois teorizar sobre a prática. Ainda segundo Piaget o desenvolvimento humano é além de muito rico esplendidamente diversificado, cada individuo possui características próprias que as diferenciam umas das outras, em seu próprio ritmo de desenvolvimento, a singularidade de cada ser humano produz seu avanço e suas mudanças. Aa pedagogia se enquadra nesse contexto, pois dela vem à segunda fase do nosso aprender.

Palavras Chave: Pedagogia da Alternância, Ensino, Aprendizagem.

RESUMEN: Aquí se discute la pedagogía en tres zonas, rural, de campo y de alternancia. La pedagogía ofrece numerosas formas de enseñanza / aprendizaje en cualquier espacio o territorio donde la voluntad de aprender, la búsqueda del conocimiento o incluso el deseo de saber. Este conocimiento proviene de la familia, los amigos, la escuela, en todas partes donde vivimos. La conmutación se describen los cambios en el aprendizaje dentro descriptiva, los antecedentes culturales de cada individuo, grupo, familia, amigos o incluso los grupos más religiosos. Esta metodología educativa se inicia a partir de los años 90 y se basaba en artículos científicos. Este método está implícito en la propuesta de Jean Piaget, hacer entender, es decir, primero la práctica, entonces teorizar sobre la práctica. Si bien el desarrollo humano va más allá de Piaget rico maravillosamente diversa, cada persona tiene sus propias características que los diferencian de los demás, a su propio ritmo de desarrollo, la singularidad de cada ser

\footnotetext{
${ }^{1}$ Godinho, Edna Maria Silva Oliveira. Graduada em Geografia pela UFG, 2006 e Pós Graduada em Educação Ambiental UFG, 2008. ednaufg@gmail.com
} 
humano produce su avance y sus cambios, la pedagogía curso se inscribe en este contexto, ya que es la segunda fase de nuestro aprendizaje.

Palabras clave: Pedagogía de la Alternancia, Enseñanza, Aprendizaje.

SUMMARY: Here is discussed pedagogy in three areas, rural, field and Alternation. The pedagogy offers numerous ways for teaching / learning in any space or territory where the willingness to learn, the search for knowledge or even the desire to know. This knowledge comes from family, friends, school, everywhere where we live. The switching describes changes for learning within descriptive, cultural background of each individual group, family, friends or even most religious groups. This educational methodology starts from the 90s and is basing on scientific articles. This method is implicit in the proposal of Jean Piaget, do to understand, ie, first practice, then theorizing about the practice. Although Piaget human development is beyond rich splendidly diverse, each individual has its own characteristics that differentiate them from each other, at their own pace of development, the uniqueness of each human being produces its advance and its changes, course pedagogy falls within this context since it is the second phase of our learning.

Keywords: Pedagogy of Alternation, Teaching, Learning.

\section{INTRODUÇÃO}

Este trabalho pretende abordar algumas representações simbólicas no universo dos camponeses/as no Brasil, bem como no Estado de Goiás, a luta para terem direito de uma alternativa de educação rural a partir da Pedagogia da Alternância. Quanto aos procedimentos de pesquisa, foram combinadas várias abordagens, como a leitura da bibliografia pertinente ao tema, particularmente o material publicado em decorrência do trabalho apresentado por Souza, 2007- GT:14 Sociologia da Educação.

Antes é visto a necessidade de fazer aqui uma analogia entre Pedagogia rural, do campo e da Alternância. A Pedagogia da Alternância é uma proposta diferenciada e alternativa que se constitui no universo pedagógico como sendo uma pedagogia da resistência cultural em relação à forte hegemonia neoliberal presente na educação brasileira, principalmente, a partir da década de 90 em diante (NASCIMENTO, 2003).

Alternância significa o processo de ensino-aprendizagem que acontece em espaços e territórios diferenciados e alternados. O primeiro é o espaço familiar e a comunidade de 
origem (realidade); em segundo, a escola onde o educando/a partilha os diversos saberes que possui com os outros atores/as e reflete-se sobre eles em bases científicas (reflexão); e, por fim, retorna-se a família e a comunidade a fim de continuar a práxis (prática + teoria) seja na comunidade, na propriedade (atividades de técnicas agrícolas) ou na inserção em determinados movimentos sociais. A Pedagogia da Alternância baseia-se num método científico.

\section{OBJETIVO GERAL}

Observar, ver, descrever, refletir, analisar, julgar e experimentar, agir ou questionar (através dos Planos de Estudos na família, comunidade ou na escola), procurar responder às questões (através das aulas, palestras, visitas, pesquisas, estágios) e experimentar (fazer experimentar em casa a partir do aprofundamento). Este método está implícito na proposta de Jean Piaget, fazer pra compreender, ou seja, primeiro praticar, para depois teorizar sobre a prática.

\section{DISCUSSÃO}

O princípio é que a vida ensina mais que a escola, por isso, o centro do processo ensino-aprendizagem é o aluno e a sua realidade. A experiência sócio-profissional se torna ponto de partida no processo de ensinar e, também, ponto de chegada, pois o método da alternância constitui-se no tripé ação reflexão ação ou prática teoria prática. A teoria está sempre em função de melhorar a qualidade de vida. Alternância significa o processo de ensino-aprendizagem que acontece em espaços e territórios diferenciados e alternados.

O primeiro é o espaço familiar e a comunidade de origem (realidade); em segundo, a escola onde o educando partilha os diversos saberes que possui com os outros atores e reflete sobre eles em base científica (reflexão); e, por fim, retorna-se a família e a comunidade a fim de continuar a práxis (prática + teoria) seja na comunidade, na propriedade (atividades de técnicas agrícolas) ou na inserção em determinados movimentos sociais. As Casas Familiares Rurais tiveram início na França em 1935 no povoado de Lot et Garonne. A iniciativa partiu de um grupo de pais agricultores que buscavam solucionar dois grandes problemas. 
De um lado, as questões relacionadas ao ensino regular que, por ser direcionado para as atividades urbanas, levava os adolescentes campesinos a abandonar a terra. E de outro lado, a necessidade de fazer chegar ao campo a evolução tecnológica de que precisavam. Criaram então a primeira Casa Familiar Rural, lá chamada de Maison Familiale Rurale, onde os jovens passavam duas semanas recebendo conhecimentos gerais e técnicos voltados para a realidade agrícola regional e duas semanas nas propriedades rurais, aplicando os conhecimentos recebidos. Tal prática foi chamada de Pedagogia de Alternância.

A educação rural no Brasil apresenta uma série de elementos os quais aparecem na legislação, nas instituições pedagógicas, no currículo e mesmo nas "recomendações" dos organismos internacionais, que possibilitam traçar um esboço da educação rural brasileira a partir dos anos 30. Para a maioria das famílias rurais a passagem pela escola básica rural (do primeiro ao oitavo ano) é a única oportunidade em suas vidas de adquirir as competências que lhes permitiriam eliminar as principais causas internas do subdesenvolvimento rural. Infelizmente, essas escolas não estão cumprindo com esta importantíssima função emancipadora de dependências e de vulnerabilidades; porque os seus conteúdos e métodos são disfuncionais e inadequados às necessidades produtivas e familiares do meio rural.

Nas referidas escolas se entedia as crianças exigindo-lhes que memorizem temas de escassa e duvidosa relevância; e não se lhes ensina de maneira criativa, participativa e prática aquilo que realmente necessitam aprender para tornarem-se mais autoconfiantes, mais empreendedores, mais auto-gestores e mais auto-dependentes. Das referidas escolas continuam ingressando gerações de futuros agricultores, agricultoras, pais e mães de família, com baixíssima auto-estima, sem os conhecimentos, sem as atitudes e sem os valores que necessitam para serem agricultores mais eficientes, melhores educadores dos seus filhos e solidários protagonistas das suas comunidades.

As escolas rurais deveriam formar cidadãos dotados de mais autoconfiança pessoal e auto-suficiência técnica, de modo que possam ser eficientes corretores das suas ineficiências e ativos solucionadores dos seus próprios problemas. Adicionalmente essas escolas deveriam outorgar-lhes uma formação valorizadora que lhes inculque melhores hábitos (amor ao trabalho bem executado, iniciativa e disciplina, perseverança e desejo de superação, cooperação e solidariedade, honradez e cumprimento dos seus deveres e responsabilidades, espírito de prevenção e previdência, etc.).

A educação básica rural deveria ter um caráter mais instrumental no sentido de proporcionar às crianças conteúdos úteis que elas possam aplicar na correção das suas 
próprias ineficiências e na solução dos problemas que ocorrem nos seus lares, propriedades e comunidades.

As unidades da Escola do Campo diferenciam-se umas das outras quanto ao conteúdo programático, adaptado à realidade de cada região, sempre de acordo com a Pedagogia de Alternância. Segundo esse método, o aluno passa duas semanas em casa e uma semana na escola. Dentre as várias formas de resistência cultural ativa existem os CEFFAs (Centros de Formação Familiares em Alternância) que compreendem, no Brasil, três experiências significativas, que são: as EFAs (Escolas Famílias Agrícolas), as CFR (Casas Familiares Rurais) e as ECR (Escolas Comunitárias Rurais) que estão unidas em torno de uma mesma pedagogia, a saber: a Pedagogia da Alternância.

Em Goiás, a primeira experiência nasceu em 1992 com a fundação da Escola Família Agrícola de Goiás EFAGO e, posteriormente, em 1998 com a fundação da Escola Família Agrícola de Orizona. As principais características das EFAs são: a responsabilidade das famílias na gestão; a alternância dos períodos entre o meio de vida sócio-profissional e a Casa Familiar; a vida dos alunos/as em pequenos grupos e em internatos; uma equipe de formadores/as; uma pedagogia adaptada. As EFAs querem proporcionar aos jovens do meio rural uma possibilidade de educação a partir da sua realidade, da sua vida familiar e comunitária e das suas atividades. Isto é feito procurando desencadear junto aos jovens um processo de reflexão e ação que possa transformar essa mesma realidade. 


\section{CONSIDERAÇÕES FINAIS}

A Pedagogia da Alternância é uma alternativa para a Educação no campo, já que o ensino nesse contexto não contempla as especificidades e as necessidades da população que vive no meio rural. Alguns problemas educacionais encontrados nas escolas no meio rural dão origem à necessidade de uma proposta educacional específica para o campo. Alguns problemas que podem ser enumerados são: a escola desvinculada da realidade local, a falta de recursos para atividades básicas do campo, a necessidade dos alunos ficarem na propriedade com sua família para trabalhar e terem dificuldades de acompanhar o calendário tradicional das escolas, a desvalorização da escola multisseriada e a falta de vagas nas escolas agrotécnicas.

De maneira geral, a Pedagogia da Alternância trabalha com a experiência concreta do aluno, com o conhecimento empírico e a troca de conhecimento com atores do sistema tradicional de educação, e também, com membros da família e da comunidade na qual vive o aluno e que podem fornecer-lhe ensinamentos sobre aquela realidade. Segundo Gohn (2001), a família é caracterizada como espaço de educação informal que acontece nos processos espontâneos ou naturais, ainda que seja carregado de valores e representações, como é o caso da educação familiar. A educação não formal se dá na intencionalidade de dados sujeitos em criar ou buscar determinadas qualidades e/ou objetivos. Neste sentido, a educação não formal está presente no bairro-associação, nas organizações, nos movimentos sociais, nas igrejas, nos sindicatos, nos partidos políticos e nas ONGs.

\section{BIBLIOGRAFIAS}

ARROYO, Miguel G. Educação Básica e Movimentos Sociais. In: VV.AA. A educação básica e o movimento social do campo. Brasília: UnB, 1999.

BRANDÃO, Carlos Rodrigues. A educação como cultura. $2^{\text {a }}$ edição. São Paulo: Brasiliense, 1985. ESCOLA RURAL: URBANIZAÇÃO E POLÍTICAS EDUCACIONAIS, Sérgio Celani Leite, 120 págs., Ed. Cortez.

GOHN, Maria da Glória. Educação Não-Formal e Cultura Política. 2a edição. São Paulo: Cortez, 2001. PEDAGOGIA DA RESISTÊNCIA CULTURAL: Um pensar a educação a 
partir da realidade campesina. Nascimento, Claudemiro Godoy. Texto apresentado no VIII Encontro Regional de Geografia (EREGEO) na Cidade de Goiás em 27/10/2003.

PIAGET, Jean. O Nascimento da inteligência na criança. 4. ed. Rio de Janeiro: Zahar, 1982.

QUEIRÓZ, João Batista P. O processo de implantação da Escola Família Agrícola (EFA) de Goiás. Dissertação de Mestrado (Educação). Goiânia: FE/UFG, 1997. TÍTULO: A Pedagogia da Alternância e o Desenvolvimento Sustentável Solidário. Ministério do Desenvolvimento Agrário, 1999.

SOUZA, João Valdir Alves de. PEDAGOGIA DA ALTERNÂNCIA: UMA ALTERNATIVA CONSISTENTE DE ESCOLARIZAÇÃO RURAL?

A Educação Camponesa como espaço de resistência e recriação da cultura: um estudo sobre as concepções e práticas educativas da Escola Família Agrícola de Goiás EFAGO. Dissertação de Mestrado (Educação). Campinas: FE/Unicamp, 2003. 